\title{
Creating new path for Old Industrial Areas: A Case Study on Dalian city, China
}

\author{
Yimei Yin and Zhigao Liu
}

\begin{abstract}
Yimei Yin, Tourism Institut of Beijing Union University, Beijing, China (yinyimei@hotmail.com)
Zhigao Liu, Institute of Geographical Sciences and Natural Resources Research, CAS, Beïing, China (liuzhigaochina@hotmail.com)
\end{abstract}

\begin{abstract}
The formation of new industries has recently been widely studied, but little research attention has been paid to the formation of new industries in old industrial districts, especially in transitional countries such as China. Based on fieldwork and rereading historical archives, this paper uses an example of Dalian tourism cluster to contribute to understanding the emergence of new economy in old industrial areas in a transitional country. The Section 2 of this paper will provide the theoretical framework from evolutionary economics for my empirical study. In Section 3, this paper will discuss the main characteristics of the decline of old industrial areas in Northeast China and the significances of developing new economy to revitalizing old industry areas. Section 4 will introduce the transitional history of Dalian economy from a high industrial region to a new economy city and also provides descriptive information about the development process of Dalian tourism industry. In Section 5, this paper will probe into the dynamics of the Dalian tourism cluster, from viewpoints of co-evolution and co-adaptation of firm, technology and institutions. Finally, we will give some policy suggestions of how to foster and promote new industries in old industrial areas, especially for transitional countries.
\end{abstract}

Keywords: new economy, old industrial area, industrial cluster, Dalian in China, transitional economy, evolutionary economic geography, coevolution and coadoption

\section{Introduction}

Within the field of economic geography, the study of old industrial regions (OIRs) is a worldwide research topic. This topic consists of two intertwined research tasks, namely, the decline of the sectoral/regional economy, and the formation of new industries and revitalization of the regional economy. Today much of industrialization activities, as well as this restructuring of old industrial areas, has shifted from North America and Western Europe to Newly Industrialized Countries in Asia. Despite this, most such cases have been discussed in the context of Western industrialized countries. Asian Newly Industrialized Countries, until quite recently, have received little attention from the international academic community (Hassink and Shin, 2005).

Like Europe and North America, China has also suffered from the general downturn in areas of heavy manufacturing industry, such as steel production and chemical production and engineering. Northeast China, including Heilongjiang, Jilin and Liaoning provinces, is home to numerous old industrial bases (NOIBs) and is affected most strongly by this downturn. While it was an economic powerhouses after the Chinese Communist Party came into power, since the economic reforms in the late 1970s, economic, social and environmental issues have emerged in these NOIBs. This include poor economic performance, low income of workers, innumerable ill-managed enterprises at the brink of bankruptcy, excessive job loss, worsening air pollution and ecological deterioration. Dalian city, however, seems to be an exception, and has been 
successfully transformed from a time-honored coastal heavy industrial city into a leading center of the service-based economy with relatively outstanding economic performance in both old and new industries.

Recently, evolutionary economic geography has attempted to contribute to understanding the fall and (re)rise of OIRs (for a detailed review, see Hassink and Shin, 2005; Hassink, 2007; Schamp, 2005), by employing concepts including path dependence, lock-in, path creation, related variety, co-evolution, sunk costs, cluster life cycles and the learning region (Grabher, 1993; Martin and Sunley, 2006; Hassink, 2007, 2010). In literature on old industrial regions employing the concepts of 'path dependence' and 'lock-in', history is often conceived as a constraint for redevelopment, and old industrial regions are thought to have little opportunity to recover from external shocks. We believe that this linear thinking is too pessimistic and argue that old regions can be resilient and have potential capability to adjust and create new paths after a disturbance. We aim to improve our empirical understanding of the regional industrial transformation from a heavy industry-dominated economy into a service-oriented economy in the context of China's larger transition from a planned to a market economy. We do not intend to compare either the character of origin old industrial bases in the West with their Chinese counterparts, but instead to better understand the Chinese cases. Hence, this paper contributes to a long-standing but important theoretical debate on why some cities diversify and others do not. This debate often makes reference to the distinction between urbanization (Jacobs) externalities and localization (Marshallian) externalities. Frenken and his colleagues clearly pointed out that the complementarities of urbanization externalities and localization externalities are captured by the notion of related variety and it is therefore essential to make an analytical distinction between agglomeration economies based on related variety, and agglomeration economies based on unrelated variety (Frenken et al., 2007). However, this presents the unsolved question of how to diversify a region's economy beyond agglomeration economies based on related variety. This paper tries to address this question and will take Dalian - a coastal city in northeastern China - as an example to show how this a leading heavy industry based city successfully transformed into a city with a competitive service-oriented economy.

The analysis is based on empirical evidence from China's Northeastern Old Industrial Bases (NOIBs), and goes beyond the traditional concept of "path dependence" developed by Paul David (1985) and Brian Arthur (1994 a, b). Since the coherent and continuous statistical data necessary for a suitable time range is not available, we turn to qualitative material collected through forty-five in-depth interviews and through secondary sources. These interviews with managing directors, academic experts and local government officials were carried out under the support of Dalian Tourism Administrative Bureau in November and December of 2005. The semistructured interviews focused on internal and external factors influencing history, firm development, and changes to and the influence of local and central policies and incentives. Secondary source included firm websites and local newspapers. These two approaches enable longitudinal studies. In the following theoretical section, the paper will build up a theoretical base, beyond the traditional concept of path dependence, for explaining the economic resilience of old industrial regions. Section 3 will describe the evolutionary processes of the Dalian Old Industrial Base, particularly the role of the tourism industry in creating a new path for Dalian's economy. A short conclusion will be presented in the final section.

\section{Path Dependence, Path Creation, Resilience in old Industrial regions}


Quite recently, both the theoretical and empirical discussion of OIRs has shifted from focusing on the understanding of regional/industrial trajectories leading to failure to the discussion on path branching leading to technologically diversified economies (Hassink, 2007, 2010; Schamp, 2005; Liu 2009). In early works on the fall of old industrial regions, the concept of "path dependence", developed by was Paul David (1985) and Brian Arthur (1994a, b), was often employed. This concept highlights the importance of small, historically contingent 'accidents' or 'chance events' which can have long-run effects on the future path of the economy, technologies, organizations and systems and makes us be increasingly aware of the importance of "history" in understanding the ways in which a thing evolves (see Martin and Sunley 2009, Liu, 2009). The path dependence concept also gives rise to the debate on the influence of chance versus necessity (Kwasnicki, 1994). Historically, the concept of path dependence is no foreign to economic geographers (see Matin and Sunley, 2009; Liu, 2009). In most of the applications of the path dependence concept, typically in understanding old industrial regions, "path dependence" is seen as a negative feature, whereby a region or locality becomes over-reliant on a particular self-reinforcing industrial-technological path that renders the regional economy increasingly structurally and technologically rigid, restricting its capacity to absorb new ideas, and ultimately limiting its ability to effectively respond to changing competitive environments. Amongst these applications, Grabher's (1993) concept of "lock-in" is the most thorough and convincing. However, the David-Arthur path-dependence model is constantly confronted with challenges and criticisms, many stemming from problematic simplifications (Sydow et al., 2005; Meyer and Schubert, 2007). Hence, Martin and Sunley made an appeal for constructing an open, non-equilibrium conception of path dependence, by paying more attention to the theoretical and empirical study of path creation.

Several concepts have emerged in response to the criticism of path dependence, and the most successful among these is "path creation". This concept, developed by Raghu Garud and Peter Karnøe (2001, 2003), offers solutions to some of the most problematic simplifications of path dependence, and argues that the creation of a new path (endogenous path creation) is a process of "mindful deviation" benefiting from conscious strategic choices, and deliberate mindful action (Garud and Karnøe, 2001, 2003). This concept proposes a significant shift from research "describing our past worlds" to research on "shaping our current states" (Liu, 2009). Garud and Karnøe (2001, p. 2) criticize the way in which proponents of a path dependence perspective often celebrates historical accidents to explain the emergence of novelty and relegate human agency to "choosing to go with a flow of events" that actors have little power to influence in real time. It means that the genesis of novelty becomes a black box and the concept of path dependence cannot offer space for new path creation, except from an external shock. However, in the endogenous path creation model, already established regional paths are likely to be mindful deviatiations, which have successfully created new paths by disembedding from the existing cognitive structure through significant strategic actions (Pham, 2006/2007).

Economic geographers have increasingly argued that a regional economy has the ability to recover successfully from shocks and that regions are economically resilient, at least in theory (see Hassink, 2010; Simmie and Martin, 2010). But why can some regional economies renew themselves and avoid lock-in, while others are locked in to decline? This debate is related to a long ongoing discussion on the relationship between specialization or agglomeration economies based on related variety and diversification or agglomeration economies based on unrelated variety. This is similarly related to the 
trade-off between fast and short-lived regional growth and long-term regional economic stability. Simply speaking, variety in the case of agglomeration economies based on related variety is seen as a source of regional knowledge spillovers that leads to a shortterm economic growth but decline in the long term, while variety in the case of agglomeration economies based on unrelated variety is seen as a portfolio protecting a region from external shocks in the long term (Simmie and Martin, 2010). However, we have little knowledge about how regions successfully transition from unsustainable but productive short-term localization economies towards long-lived regional economic stability. So, what is the role of historical legacies (for example, the established economic structure and relational infrastructures between actors) in creating new regional path? This paper tries to give answers to these issues, taking Dalian as an example to show how this city that is traditionally a leader in heavy industry in China successfully developed a competitive service-oriented economy.

\section{The Overview of Dalian's Regional Industry Restructuring}

\section{The Relative Decline of Dalian as an Old Industrial Base}

Dalian, located on the southern tip of Liaodong peninsular in Northeast China, is the marine gateway for Northeast China and Northeast Asia. While its geographic location as China's northernmost seaport makes it a perfect place for industry, Dalian was only a small fish village before the Opium War in 1840. Industrialization started during the period of Russian and Japanese colonization from 1898 to 1945, with heavy industrial factories built by these colonists. Since then, Dalian had become the leading northeast coastal city of heavy industries such as shipbuilding, machinery manufacturing, industrial chemicals, and steel-making, After the Communist Party came to power, these industries were further expanded and by the middle of 1980s, Dalian had grown into one of the important industrial cities in NOIBs. As the reform and opening-up policy was implemented in 1979, the state-owned heavy industrial enterprises, operated under the state-monopoly regulation and state ownership, began to suffer with declining economic performance and high unemployment.

\section{The Bifurcation of Dalian's regional path through the development of the Tourism Industry}

The Dalian undertook a unique path in successfully transforming from a timehonored heavy industrial economy into a competitive service-oriented economy. During the lengthy process of reshaping the regional path, the tourism industry plays a historically significant role. Dalian city separated itself from the established regional development path of traditional heavy industries by developing this industry that is technologically very different from heavy industries. The rapidly growing tourism industry in Dalian not only improved physical infrastructure such as communications and transportation, but also supported business-friendly social environments, which in turn were helpful in attracting increasing numbers of foreign investors and multinationals and in fostering local private entrepreneurship. Because of its crucial role, before discussing Dalian's industrial restructuring, we will first talk about the development of Dalian's tourism industry.

Compared with most other touristic cities in China, Dalian's tourism industry has a relative long history that can be traced to the beginning of 1950s when specialized tourism agencies were first set up to meet the needs of foreign visitors. In 1954, Dalian became one of the first cities in which a national tourism agency (China International Travel Service), but at this time the tourism industry only existed for political purposes 
such as serving for state cadres' vacation or receiving foreign guests from other socialist countries.

As economic reform and the opening up policy was pursued in China, the Dalian city government began to realize the economic value of its natural resources from beautiful beaches to mountains and countless rivers and streams, and in 1980 set up a tourism industry office responsible for the promotion of this industry. The first citylevel tourism planning in China, "Dalian ten-year tourism development plans" was drafted the same year. Meanwhile, infrastructure construction and employee training programs also began to be put on the agenda. This relatively early development of the tourism industry gave Dalian the first mover advantage in establishing its leading position in the domestic tourism industry.

After more than 20 years development, tourism as a growth pole became a dynamic driving force for the local economy in Dalian. According to the statistical data on the overall tourism development in Dalian from 1992 to 2005, growth in the total income from tourism and the tourism foreign exchange earnings were growing year by year (except for in 2003 due to the SARS crisis) and the total tourism income reached 21.09 billion RMB in 2005, equivalent to 9\% of Dalian total GDP. Today Dalian has developed from a purely sightseeing city into an integrated tourism city catering to sightseeing, leisure and vacation, meeting and exhibition tourism.

\section{Expanded Tourism Strategy and Resurgence of Local Economy}

As we have pointed out, Dalian started to diversify its regional economies through developing the unrelated variety industry of tourism, rather than through related diversification. At the same time, the economically successful development of Dalian's tourism industry is not based on regional industrial heritages, at least until quite recently where industrial heritages have been exploited, but on historically accumulated advantages, geographical location, and recently innovation and agglomeration advantages.

In the development course of the tourism industry, the local state played a very important role in forming place-specific advantages. The advantageous natural location endowed Dalian with a competitive geographical advantage, but the prosperity of Dalian tourism industry has also benefited from local institutional innovation. Local natural resources such as beautiful beaches and landscapes were exploited and basic physical infrastructures were constructed as early as the early 1980s. Dalian was one of the earliest tourism destinations in Northeast China for overseas and inland travelers. This first mover advantage laid a sound foundation for future growth of the tourism industry and by the middle of the 1990s, Dalian had already positioned itself as the most popular city for tourism in Northeast China.

The rapid growth of the Dalian tourism industry and its contribution to the local economy encouraged the Dalian city government to further develop the tourism industry with great ambition. As early as 1987, an official "Dalian tourism committee" was set up to coordinate the development of this industry. Since then, a series of policies and measurements have been adopted and specialized infrastructure for tourism and market regulation environment have been developed. Both the domestic market and the overseas market began to be well exploited and Dalian was awarded the title of "Excellent Tourism City China" in 1998, furthering its reputation as a tourist destination.

It is worth mentioning that the former Mayor, Bo Xilai, played an important role in dynamically promoting Dalian's tourism industry during the period of industrial restructuring in Dalian. Enlightened by the development practices of globally known 
tourist desinations, particularly Hong Kong, he jumped from a "small tourism strategy" to an "expanded tourism strategy". In the small tourism strategy, tourism was considered as a small but key component of the economy. Consequently, the interaction between the tourism administration department and other related government agencies such as city planning was weak. During Bo's tenure (1993-1999), the Dalian city was positioned as "North Hong Kong", and a series of innovative measures were launched, including "the city brighten project", and "the city greening project". Meanwhile, some heavy industrial and chemical plants were moved from the inner city to free urban space for new service industries. According to statistical data in 2005 the Dalian tourism industry provided 230 thousand employment opportunities directly and 1150 thousand indirectly, and nearly a quarter of local residents worked in jobs related to the sector. As the tourism industry provided greater employment for local people and increased individual income, the local residents became involved in and enthusiastic about its further development. By the end of 2007, there were 378 tourist agencies and 206 tourist hotels (restaurants), 166 of which are star-rated. Today Dalian's tourism industry is in a leading position in China.

The introduction of the expanded tourism strategy served as a new starting point. It not only provided a blueprint for the tourism industry that harnessed Dalian's unique identity as a romantic tourism destination, but also developed a business-friendly environment which was beneficial to the whole economy. This expanded tourism strategy was the result of close collaboration between the public and private sectors. More importantly, it enhanced the awareness of environment protection and service quality, and this greatly benefited the resurgence of the local economy. In 2002, the United Nations Environment Programme (UNEP) awarded Dalian the title of "global best 500 in environment".

In recent years, the central government has began to reconsider the development of the old industries in Northeast China, and the local authorities bagen to seek new ways of promoting the regional economy. The central government began the "Northeast China Rejuvenation Program (NCRP)" in 2002. This program propelled the renewal of heavy industry and the emergence of new industries. During the period of "the tenth five-year plan" (2001-2005), the Dalian city government began to target the heavy manufacturing industry as the outlier of the local economy, exploring strategies for transforming the state-dominated heavy industrial system into a market-oriented sytem. This stimulated the formation of local private entrepreneurship, encouraging the formation of firms, including hi-tech enterprises.

The rapid development of the tourism industry in Dalian not only improved physical infrastructure such as communications and transportation, but also constructed a business-friendly social and institutional environment, which in turn attracted increasing number of foreign investors and multinational firms and fostered local private entrepreneurship. Encouraged by these changes, local and foreign investors have founded an increasing number of startups in both traditional industries such as the chemicals and machine-making and high-tech industries such as software and information technology. Additionally, by reorganizing state-owned enterprises and attracting foreign direct investment the existing large-scale petrochemical production, shipbuilding and equipment manufacturing industries have been revitalized. Today these have become key economic sectors of the regional economy in terms of both economic output and employment. Dalian is now one of China's top five cities in terms of centralized foreign companies, the has the largest amount of foreign investment of any city in Northeastern China. Dalian is home over 10 thousand foreign ventures, 69 of 
which are Global 500 firms, and many firms based elsewhere have chosen to establish their eastern region headquarters in Dalian.

Owing to the increasingly improved business environments, service industries such as logistics, exhibitions and fairs and information processing are emerging as a major economic engine, underwriting the next generation of wealth and employment creation. Dalian is identified today as one of the most important international shipping center in Northeast Asia, and the largest cargo transshipment hub in the region. Dalian is the biggest transfer port for grain and oil in China, and processes more than 70 percent of the seaborne cargo and more than 90 percent of the container transport of Northeast China. Zhoushuizi International Airport is serviced by 22 international airlines and is the $4^{\text {th }}$ largest airport in China in terms of number of airlines and flights.

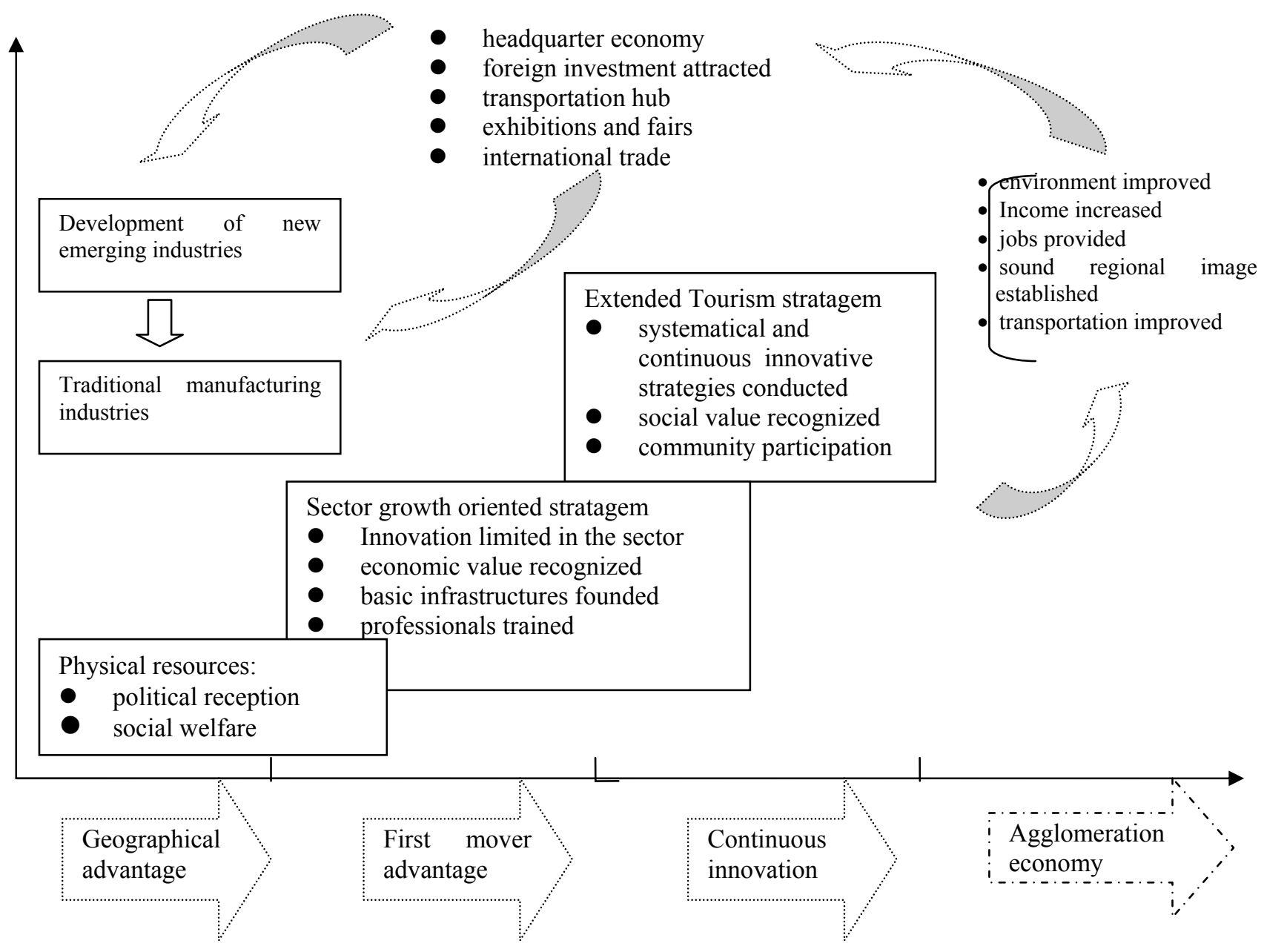

Figure 1: The Interaction of Tourism Industry and Old Industries in Dalian

\section{Conclusion}

The decline and rejuvenation of old industrial regions has become a hot topic in economic geography in the past decades. Quietly recently, research has shifted from "describing our past worlds" through such concepts as path dependence and lock-in to studying "creating the new path". We argue that regions are economically resilient, and explore why some regional economies can renew themselves and avoid lock in while others are locked in to decline (Martin and Sunley, 2006). Scholars studying old 
industrial region often use these concepts of evolutionary economics such as path dependence and lock-in which see the history of regions/industries as primarily burdens that hinder the development of old industrial regions. However, we do not fully agree with this linear thinking and argue that old industrial regions can potentially adjust, recreating a new path after a disturbance. In this regard, this paper took Dalian, a rising city in the service economy of northeast China, as an example to study the evolutionary path and characteristics of Chinese old industrial bases, with the ambition of a theoretical examination of an ill-defined concept of path dependence.

The industrial restructuring in Dalian and in the old industrial cities in West Europe and North America are by no means the same in either character or origin. These differences are manifested in two ways: first, the emergence and development of old industries in Dalian were not driven by the market mechanism but were influenced largely by the changes in foundational and national political-economic institutions; secondly, the old industrial areas declined before the industrialization process had been fully achieved. This premature decline was partially the result of influence of old regimes in newly changed environments rather than backward technology or resources exhaustion. The recent successful local economic rejuvenation in Dalian must be considered combined with the establishment of market mechanism, and the development of agglomeration economy that attracted foreign ventures, largely because of the continuously improving natural environment during the "expanded tourism strategy".

Unlike the tourism sector in the western OIRs, which was more or less built on old industry, Dalian's tourism sector largely did not make use of the local old industrial heritage. In other words, Dalian tourism industry was not built on the local old industrial base, but on its historical accumulated advantages, from geographical advantage, through the first mover advantage gained during the planned economy era, to recent continuous innovation and agglomeration economies. More interestingly, the development of the tourism industry, particularly during the late 1990s, enhanced the natural environment and regional image, and this in turn helped attract foreign investment, which boosted the redevelopment of the heavy industries and the emergence of new hi-tech industries. The increasingly improved physical environment and business-friendly social and institutional atmosphere are critical to attracting foreign direct investment necessary in revitalizing the traditional manufacturing economy and cultivating new industries such as information technology and advanced service industries such as logistics, exhibition and trade fairs and information processing.

While the past is conceived of as a constraint for redevelopment in the literature on old industrial regions, this case study shows that history should not only be regarded as a constraint, but also as heritage. As long as historical heritage is discovered and made full use of, the regional economy maintains a good chance of being revitalized. Therefore, it might be better for policy-makers to take a positive attitude towards the old industrial areas. One of the most intriguing questions for both researchers and policymakers is how recreating new paths for old industrial regions can (re)use historical heritages while introducing new technologically (un)related industries. Naturally, the concrete policies for particular regions need to be place-specific.

\section{Acknowledgements}

We would like to thank Eike W Schamp. Without his numerous readings of drafts, insightful comments, we would never have finished this article. We thank two anonymous referees for valuable comments on the previous versions of this paper and 
Raphael Stargrove for editorial assistance as well, and also acknowledges financial support from National Natural Science Foundation of China[No: 41071096].

\section{References}

Arthur, W. B. (1994a) 'Path dependence, self-reinforcement and human learning', In Pyke, F. et al. (eds), Increasing Returns and Path Dependence in the Economy. (Michigan: Michigan University Press, 133-158).

Arthur, W B. (1994b) Increasing Returns and Path Dependence in the Economy. (Michigan: Michigan University Press).

David, P. A. (1985), 'Clio and the economics of QWERTY', American Economic Review, 75, 332-337.

Garud, R. and Karnøe P. (2001), 'Path creation as a process of mindful deviation', in R. Garud and P. Karnoe (eds). Path Dependence and Creation. (Mahwah, NJ: Earlbaum).

Garud, R.and Karnøe P. (2003), 'Bricolage versus breakthrough: distributed and embedded agency in technology entrepreneurship'. Research Policy, 32: 277300.

Grabher, G. (1993), 'The weakness of strong ties: the lock-in of regional development in the Ruhr area', In G Grabher (eds). The Embedded Firm: On the Socioeconomics of Industrial Networks ( London: Routledge, 255 - 277).

Hassink R., Shin D-H (2005), 'The restructuring of old industrial areas in Europe and Asia', Environment and Planning A 37:4, 571 - 580.

Hassink R. (2007), 'The strength of weak lock-ins: the renewal of the Westmünsterland textile industry'. Environment and Planning A 39:5, 1147 - 1165.

Hassink, R. (2010), 'Regional resilience: a promising concept to explain differences in regional economic adaptability', Cambridge Journal of Regions, Economy and Society, 3:1. 45-58.

Frenken, K., van Oort, F.G., Verburg, T. (2007), 'Related variety, unrelated variety and regional economic growth', Regional Studies, 41:5, 685-697.

Kwasnicki, W. (1994), 'Chance and necessity in industrial development'. In Evolutionary Economics of Technological Change. Assessment of Results and New Frontiers, vol.1, 79-98, European Parliament, Strasbourg October 6-7-8, 1994.

Liu zhigao, (2009), The Emergence of Clusters in Societal Transition: A Coevolutionary Perspective to the TCM Cluster in Tonghua/China, Doctoral Dissertation, Frankfurt University

Martin R. (1999), 'The new 'geographical turn' in economics: some critical reflections', Cambridge Journal of Economics 23, 65-91.

Martin, R. and Sunley, P. (2006), 'Path Dependence and Regional Economic Evolution', Journal of Economic Geography, 6:4,395-437.

Martin, R. and Sunley, P. (2009), 'The place of path dependence in an evolutionary perspective on the economic landscape'. In Boschma, R.A., R. Martin (eds). The Handbook on Evolutionary Economic Geography. (Cheltenham: Edward Elgar).

Meyer, U. and Schubert, C. (2007), 'Integrating path dependency and path creation in a general understanding of path constitution'. Science, Technology and Innovation Studies, 3:1, 23- 44.

Pham ,X. 2006/2007). 'Five principles of path creation'. Oeconomicus, Volume VIII, 5-17 
Schamp, E. W. (2000), Vernetzte Produktion. Industriegeographie aus institutioneller Perspektive(Networked production. Industrial geography in an institutional perspective). Darmstadt: Wissenschaftliche Buchgesellschaft.

Schamp E. W. (2005), 'Decline of the district, renewal of firms: an evolutionary approach to footwear production in the Pirmasens area, Germany', Environment and Planning $A$ 37:4, 617 - 634

Sydow Jörg, Georg Schreyögg, and Jochen Koch (2005), 'Organizational paths: path dependency and beyond', 21st EGOS Colloquium, June 30 - July 2, 2005, Berlin, Germany.

Simmie, J. and Martin, R. (2010), 'The economic resilience of regions: towards an evolutionary approach'. Cambridge Journal of Regions, Economy and Society

Frenken, K. (2007), 'Applied Evolutionary Economics and Economic Geography (Cheltenham: Edward Edgar).

Garud, R. and Karnøe, P. (2001), 'Path creation as a process of mindful deviation', in R. Garud and P. Karnoe (eds), Path Dependence and Creation. (Mahwah, NJ:Earlbaum,1-38)

Simmie, J. and Martin, R. (2010), 'The economic resilience of regions: towards an evolutionary approach'. Cambridge Journal of Regions, Economy and Society. 